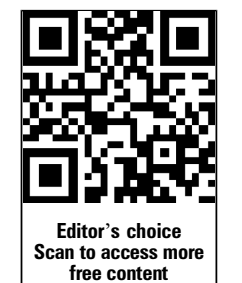

${ }^{1}$ Barcelona Clinic Liver Cancer (BCLC) Group, Liver Unit, Hospital Clinic Barcelona, IDIBAPS, University of

Barcelona, Barcelona, Spain

${ }^{2}$ Centro de Investigación

Biomédica en Red de

Enfermedades Hepáticas y

Digestivas (CIBERehd), Spain

${ }^{3}$ Mayo Clinic, Mayo College of

Medicine, Rochester,

Minnesota, USA

${ }^{4}$ Gastrointestinal Surgery and

Liver Transplantation, Istituto

Nazionale Tumori IRCCS

(National Cancer Institute),

Milan, Italy

Correspondence to

Dr Jordi Bruix, BCLC Group,

Liver Unit, Hospital Clínic,

C/Villarroel 170

Barcelona 08036, Spain;

jbruix@clinic.ub.es

Received 17 December 2013

Revised 3 January 2014

Accepted 19 January 2014

Published Online First

14 February 2014

\title{
Hepatocellular carcinoma: clinical frontiers and perspectives
}

\author{
Jordi Bruix, ${ }^{1,2}$ Gregory J Gores, ${ }^{3}$ Vincenzo Mazzaferro ${ }^{4}$
}

\section{ABSTRACT}

Hepatocellular carcinoma (HCC) is one of the leading causes of cancer-related death and is currently the main event leading to death in patients with cirrhosis.

Evolving information suggests that the metabolic syndrome with non-alcoholic liver disease may be an important cause of HCC in addition to viral hepatitis and alcohol-induced liver disease. The molecular pathogenesis is extremely complex and heterogeneous. To date the molecular information has not impacted on treatment decisions. Periodic surveillance imaging of patients with cirrhosis is widely practiced, especially because diagnostic, radiographic criteria for early-stage HCC have been defined (including nodules between 1 and $2 \mathrm{~cm}$ ) and effective treatment is available for tumours detected at an early stage. Worldwide the approach to resection versus transplantation varies depending upon local resources, expertise and donor availability. The criteria for transplantation are discussed, and the controversial areas highlighted with evidencebased recommendations provided. Several approaches are available for intermediate stage disease, including radiofrequency ablation, transarterial chemoembolisation and radioembolisation; the rationale for these therapies is buttressed by appropriate outcome-based studies. For advanced disease, systemic therapy with sorafenib remains the option best supported by current data. Thus, while several trials have failed to improve the benefits of established therapies, studies assessing the sequential or combined application of those already known to be beneficial are needed. Also, new concepts are provided in regards to selecting and stratifying patients for second-line studies, which may help explain the failure of prior studies.

Hepatocellular carcinoma (HCC) is a major health problem worldwide as more than 700000 cases are diagnosed yearly. ${ }^{1}$ Major risk factors include infection with hepatitis $\mathrm{B}$ or $\mathrm{C}$ viruses, and alcoholrelated cirrhosis. Non-alcoholic steatohepatitis has recently emerged as a relevant risk factor. Smoking increases the risk and coffee may diminish it. The mortality rate in most countries almost equals the incidence rate, indicating the lack of effective therapies at diagnosis. ${ }^{1-3}$ In Japan, where HCC surveillance is aggressively practiced resulting in identification and treatment of early-stage HCC, the incidence rate exceeds the mortality rate (boxes 1-3).

In more than $90 \%$ of the cases, HCC develops within an established chronic liver disease, namely cirrhosis. ${ }^{1-3}$ Thus, HCC can be prevented by avoiding the acquisition of risk factors for chronic liver disease. Vaccination and antiviral treatment will have a positive impact, but if antiviral intervention is delayed until the establishment of cirrhosis, preventive efficacy will be diminished. ${ }^{4}$ Long-term interferon treatment does not reduce HCC risk, and agents such as metformin, propranolol and retinoids deserve to be tested prospectively. ${ }^{5-9}$

In this review, we examine the current understanding and future challenges in three major areas: molecular events that drive tumour development and progression, outcome prediction and currently available treatment options.

\section{MOLECULAR CLASSIFICATION OF HCC: WHAT HAVE WE LEARNED?}

The molecular era of medicine was anticipated with great expectations so that the molecular genesis of cancer would be unravelled quickly with great benefits for patients. The biomedical community hoped that we would be able to (A) easily riskstratify patients, (B) identify common and dominant oncogenic pathways and $(C)$ institute targeted and curative therapies using a personalised medicine approach (box 4). Some of these goals have been accomplished for some cancers, but progress has been slow and disappointing in many. Cancers are far more complex than realised, more genetically heterogeneous than appreciated and genetic information quite difficult to analyse from a systems biology perspective, especially pathway mapping. The nature of the genetic information is also protean. For example, genetic analysis involves transcriptional profiling often referred to as expression signatures, miRNA profiling, assessment of long non-coding RNAs, determination of copy number aberrations, deep exome sequencing, quantification of hemizygous and homozygous deletions, and promoter methylation (box 5). ${ }^{10-12}$ To further confound interpretation of the genetic analysis, there are driver mutations important in the biology of the cancer and passenger mutations which are unimportant, ${ }^{10-13}$ distinguishing between the two is not easy. The cancer genetics must also be compared with non-tumour tissue to identify cancerspecific alterations. The cancer programme also varies over time, and hence genetic features critical for carcinogenesis may vary from the metastasis genetic programme ${ }^{14}$; such a process likely evolves via clonal evolution. Unfortunately, much of the human material available for genetic analysis comes from surgical specimens and therefore reflects only a small subset of patients. Cancer genetic heterogeneity is extremely impressive; not only are there differences between patients, but between tumour nodules in the same patient, and even within a single tumour nodule (figure 1). ${ }^{15}$ For example, one study employing whole-genome sequencing examining three nodules in one patient identified
To cite: Bruix J, Gores GJ,

Mazzaferro V. Gut

2014;63:844-855 


\section{Box 1 Current concepts regarding HCC}

- Hepatocellular carcinoma (HCC) is the main cause of death in patients with cirrhosis.

- In HCC not only might each patient have their own private cancer but each tumour site may be genetically unique. Genetics also may vary due to the underlying liver disease (nature of the microenvironment) and the patients' background. As a result, currently none of the existing guidelines in HCC incorporate genetic tools.

- Combining clinical, pathological and gene expression data may help in HCC prognostication. How this may impact patient selection and therapeutic strategies remains to be clarified.

- Since in most instances cirrhosis precedes HCC, regular ultrasound screening in such at-risk patients is recommended. Diagnostic work-up should be initiated when nodules of at least $10 \mathrm{~mm}$ are detected.

- For outcome prediction, treatment planning and research, the Barcelona Clinic Liver Cancer (BCLC) staging system is recommended.

- Technical feasibility of a given treatment is not a surrogate for improved patient survival. Therapeutic recommendations should consider the net difference of survival with versus survival -without a given treatment (benefit principle).

two driver mutations in one nodule due to clonal evolution and separate driver mutations in the other two. ${ }^{16}$ The intratumoural heterogeneity may reflect the existence of distinct pools of cancer stem-like cells that display different tumorigenicity and independent genomic evolution. ${ }^{17}$ Thus, not only does each patient have their own private cancer but each tumour nodule may be genetically unique within the same patient. The HCC genetics also may vary due to the aetiology of the underlying

\section{Box 2 Liver transplantation for HCC}

- Not a single therapeutic modality may fit all hepatocellular carcinoma (HCC) presentations, as patient and their disease-specific features are also crucial for decision making.

- Prediction of survival for end-stage cirrhosis without cancer is quite well captured by the MELD score while HCC lacks prognostication models applicable to various treatments and to liver transplantation.

- Organ allocation for patients with HCC is currently based on maximisation of post-transplant outcome (utility). The benefit principle helps to avoid futile transplantation on very early $(<2 \mathrm{~cm}$ in size) and in advanced tumours.

- The Milan Criteria remain the benchmark for patient selection and the baseline comparator with other suggested criteria. Modest expansion may be proposed (University of California San Francisco or Up-to-7 criteria) if not detrimental to the dynamics of the waiting list and depending upon organ availability.

- Pretransplant tumour downstaging is possible, and if tumour burden is reduced within conventional Milan Criteria, the 5 -year survival is comparable to that of HCC eligible to transplants without requiring downstaging.

\section{Box 3 Non-surgical therapy for HCC}

- Locoregional options aim to induce tumour necrosis and necrosis may not be paralleled by tumour burden reduction. EASL criteria and mRECIST take into account the degree of tumour necrosis and should guide treatment response assessment .

- Ablation competes with surgery for hepatocellular carcinoma $<3 \mathrm{~cm}$ and may be considered as first-line treatment depending on age/associated comorbidities and location of the tumour.

- Trans-arterial chemoembolisation (TACE) is the first-line option for patients with intermediate (Barcelona Clinic Liver Cancer (BCLC) B) stage. Tolerance has improved by the use of beads. Restrictive selection and proper technique result in prolonged survivals that are the benchmark when debating the benefits of surgery in patients with multifocal disease or transplantation with expanded criteria.

- Radioembolisation with Y90 microsphere may provide survival rates similar to TACE and sorafenib, particularly in the setting of portal vein thrombosis. Ongoing randomised trials should confirm this possibility.

- Sorafenib is the sole systemic agent improving patient survival with an adequate safety profile. Response to sorafenib proved that survival of cancer patients may be increased in the absence of a decrease in tumour burden. Time to progression to estimate treatment activity as a surrogate of efficacy needs refinement and validation.

- Postprogression survival is a relevant parameter in patients that receive sequential therapies. It is influenced by pattern of progression as well as by liver function impairment and presence of symptoms. All these parameters have to be taken into account in trial design and analysis.

liver disease and the patients' genetic background making comparisons of the genetic changes between different regions of the world difficult.

Unfortunately, even when oncogenic pathways are identified by genetic studies, they have proven difficult to target therapeutically. Our current pharmacological technology is much better at designing kinase inhibitors than in blocking protein-protein interactions. For example, despite the strong evidence for WNT/ $\beta$-catenin pathways in HCC, this pathway has so far been difficult to target pharmacologically.

Cancer cell reliance on an intrinsic oncogene mutation for survival has been termed oncogene addiction ${ }^{18}$; one of the

\section{Box 4 Goals of genetic studies}

Risk stratification

- Risk for developing hepatocellular carcinoma (HCC)

- Risk for HCC recurrence following 'curative' therapy

- Disease prognostication for existing HCC

Oncogene pathway identification

- Carcinogenesis

- Invasion and metastases

- Targeted therapy based on a patient's own cancer genetic profile 
Box 5 Complexity of hepatocellular carcinoma genetic proffling

Genome alterations

- Genome-wide association studies by single nucleotide polymorphisms

- mRNA expression profiles/signatures

- miRNA expression profiles/signatures

- Long non-coding RNA expression profiles/signatures

- Copy number aberrations

- Exome sequencing for mutations

- Homozygous and heterozygous deletions

- Translocations

DNA epigenetics

- Promoter methylation status

goals of genetic studies is to identify such oncogene mutations for therapeutic targeting. An example is melanomas, which commonly express a mutant BRAF gene encoding BRAF (V600E) resulting in a gain of function. ${ }^{19}$ Patients with melanomas harbouring this mutation respond to vemurafenib. ${ }^{19}$ This scenario reflects an excellent example of personalised medicine in oncology. However, the patient response rates are neither uniform nor durable.

The microenvironment is also critical in tumour biology. Recent data indicate hepatocyte growth factor secretion by adjacent stromal cells is sufficient to provide resistance to cell killing by vemurafenib. ${ }^{20} 21$ Hence, cancer therapy must be viewed more broadly than merely targeting genetic aberrations and the nature of the microenvironment will be critical in this analysis.

Given this byzantine complexity of tumour genetics, it is not surprising that meaningful progress has been difficult, and none of the existing guidelines in HCC incorporate genetic tools. In the following sections, we will dissect the available genetic information emphasising commonalities of findings as opposed to discrepancies.

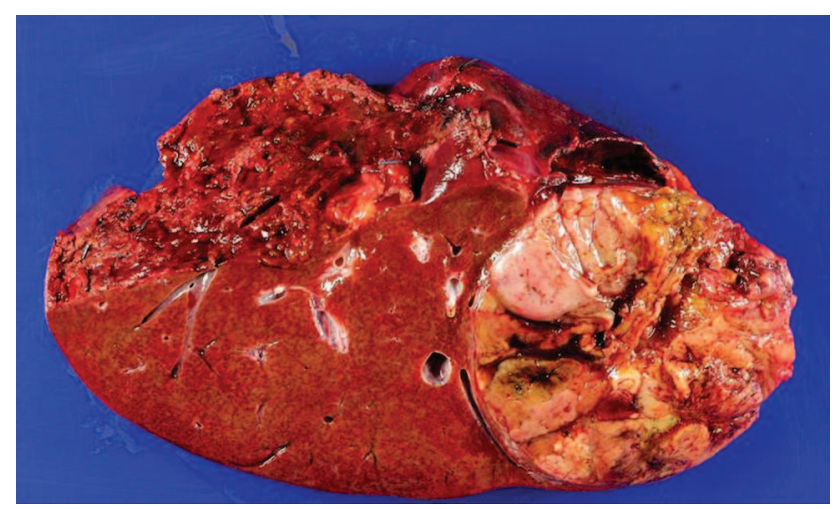

Figure 1 Macroscopic appearance of a large hepatocellular carcinoma (HCC) resected from a patient with hepatitis $\mathrm{C}$ virus cirrhosis. Note the heterogeneous appearance with some necrotic areas. This macroscopic appearance translates into a heterogeneous degree of cell differentiation, as well as proliferation activity at a microscopic level. Should not be unexpected to find heterogeneous genomic profile when trying to characterise the tumour at a molecular level. As a result, efforts to profile HCC patients through biopsy sampling with the goal to refine prognosis prediction and therapeutic target identification may be an unrealistic enterprise.

\section{Risk stratification for developing HCC}

Several genome-wide association (GWAS) studies examining single nucleotide polymorphisms have been performed, although many have not been validated in large external cohorts and suffer from methodological drawbacks. ${ }^{22-30}$ The pathways affected include oxidative stress and detoxifying pathways, iron metabolism, inflammation-cytokine-chemokine systems and DNA synthesis and repair mechanisms. ${ }^{29}$ Interestingly, functional polymorphisms in the epidermal growth factor receptor (EGFR) have also been associated with the risk for HCC. ${ }^{31} 32$ Given the availability of EGFR inhibitors, such drugs may be tested as chemopreventative strategies. Finally, somatic mutations activating telomerase reverse transcriptase promoter have been identified in cirrhotic preneoplastic macronodules and early HCC, suggesting these mutations in liver tissue could be used to identify patients at high risk for developing HCC. ${ }^{33}$

\section{Risk stratification for HCC recurrence}

One of the greatest problems plaguing potential curative treatment for HCC is the high risk of recurrence (ie, ablation and surgical resection). Expression profiling of fixed tissue HCC and non-tumour tissue has been employed to gain insight into this risk. $^{34}$ Unexpectedly, it was both the tumour and the nontumour expression signature that predicted tumour recurrence. These data are compatible with a field defect in the cirrhotic liver and indicate that most delayed tumour recurrences after curative therapy may not be metastasis from the original tumour but rather de novo cancers arising in the cirrhotic liver. Alternatively, it could also be that the surrounding liver signature identifies a more advanced liver disease with more oncogenic risk or even a specific feature that makes metastatic nesting and progression less efficient. The data identified a strong interleukin-6 (IL-6) downstream signature compatible with inflammatory cytokine-driven carcinogenesis. As disruption of IL-6 signalling reduces experimental carcinogenesis in the mouse, these data also suggest IL- 6 inhibition could be a secondary chemopreventive strategy. ${ }^{35}$ Microvascular invasion by HCC is an established risk factor for recurrence. Given this information, a molecular signature predicting vascular invasion would help to stratify the patients' risk for recurrent disease. Although an expression signature has been reported for microvascular invasion, it was not strongly predictive of recurrent disease and hence its clinical value uncertain. ${ }^{12}$ An alternative approach has been combining clinical, pathological and gene expression data to predict HCC recurrence. ${ }^{36}$ A proliferative molecular expression signature combined with the adverse nontumour molecular signature described above plus the pathological presence of satellite nodules predicted disease recurrence. ${ }^{37}$

\section{Oncogenic pathways}

mRNA expression and genome-wide methylation profiling

The large number of studies devoted to this technology has been extensively reviewed. ${ }^{11} 38$ Briefly three major pathways were identified including a WNT/ $\beta$-catenin, a proliferation and a hepatoblastoma-like pathway. The molecular signatures have been broad and without precise overlap between studies. Therefore, although informative they are unlikely to make their way into clinical practice. Furthermore, they have not elucidated specific, targetable oncogenic pathways. The same can be said of the genome-wide methylation profiles published to date. ${ }^{39}$ 


\section{microRNA (miRNA) profiling}

miRNA are small non-coding RNAs that regulate gene expression via altering transcription and/or translation of mRNA. miRNAs are relatively promiscuous and regulate on average approximately 200 target mRNAs, and therefore can affect broad cellular programmes such as cellular differentiation, cell proliferation and avoidance of cell death. ${ }^{40} \mathrm{~A}$ comprehensive analysis of miRNA expression patterns in HCC revealed dysregulation of several miRNAs ${ }^{41}$; however, no functional studies were performed to demonstrate the biology of this dysregulation. Llovet and coworkers profiled miRNA in HCV-associated HCC obtained in the USA, Italy and Spain, ${ }^{42}$ and through unsupervised hierarchical cluster analysis suggested three subsets including a $\beta$-catenin-associated subset, an interferon-responserelated gene subset and a subset associated with activation of receptor tyrosine kinase signal transduction pathways. In this last subset, miR-517a was found to be upregulated and functional analysis revealed it as a true oncomir. Whether miRNAs can be targeted therapeutically has yet to be established.

\section{Genome-wide surveys}

There are a limited number of studies in HCC using genomewide surveys. Zucman-Rossi and coworkers examined 125 surgically excised HCC in French patients for copy number analysis and performed whole-genome sequencing in 24 HCC in which the largest subset had alcoholic cirrhosis. ${ }^{43}$ The major pathways commonly altered by somatic mutations or homozygous deletions included the $\mathrm{Wnt} / \beta$-catenin pathway, the $\mathrm{p} 53$ pathway, phosphatidylinositol 3-kinase (PI3K)/Ras signalling pathways, oxidative and endoplasmic reticulum stress modulators, and processes responsible for chromatin remodelling. Of note, different mutations segregated by aetiology of the liver disease suggesting initiation of carcinogenesis may vary between different liver diseases. Inactivation of chromatin remodelers was more common in HCC from patients with alcoholic cirrhosis, whereas interferon regulatory factor 2 (IRF2; a modulator of the p53 pathway) mutations were found predominantly in HBV patients. Nakagawa and colleagues performed whole-genome sequencing in 27 HCC from Japanese patients, which were largely due to $\mathrm{HBV}$ and hepatitis $\mathrm{C}$ virus (HCV). ${ }^{44}$ They also noted mutations affecting the $\mathrm{Wnt} / \beta$-catenin, the p53 and chromatin remodelling pathways. In addition, they identified point mutations in ERRFI1, a protein that inhibits the kinase domains of EGFR and ERBB2. Loss of function of ERRFI1 may activate EGFR signalling pathways in a small subset of HCC, and mutations of ERRFI1 may serve as biomarker for EGFR-directed therapies. HBV genome insertion was also observed within or upstream of the telomerase reverse transcriptase (TERT) gene as previously identified by Roberts and colleagues, suggesting that modulation of telomerase activity is a carcinogenic mechanism in HBV patients. ${ }^{45}$ Luk and colleagues also performed a genome-wide survey of recurrent HBV integration sites in 81 HCC from HBV-positive Chinese patients. ${ }^{46}$ Recurrent genes with HBV integrations breakpoints in HCC included TERT, mixed lineage leukaemia 4 (MLL4), cyclin E1 (CCNE1), SUMO1/sentrinspecific peptidase 1 (SENP5), rho-associated, coiled-coil containing protein kinase 1 (ROCK1) and fibronectin 1 (FN1). HBV integration was associated with their upregulation implicating their dysregulation in the pathogenesis of HCC. Taken together, these studies have highlighted as new therapeutic targets the area of chromatin remodelling in a large subset of HCC.
High-resolution analysis of a single HCC genome was performed in a $\mathrm{HCV}$-positive HCC. ${ }^{47} \mathrm{~A}$ tuberous sclerosis 1 (TSC1) inactivating, nonsense substitution was identified in a subpopulation of the tumour cells, indicating a mammalian target of rapamycin (mTOR)-driven oncogenic pathway. Another high-resolution genome analysis of 18000 proteincoding genes (the exome) was in 10 patients with HCV-associated HCC identified inactivating mutations of AT-rich interactive domain 2 (ARID2). ${ }^{48}$ Given the role of this protein in chromatin remodelling complexes, it may potentially serve as a tumour suppressor modulating gene regulation or alternatively may positively regulate $\mathrm{HCV}$ propagation during HCC development. ${ }^{48}$ These high-resolution studies point additional therapeutic targets for the treatment of HCC, namely mTOR inhibitors and epigenetic modulators. ${ }^{49}$ However, progress will be slow and targeting the tumour microenvironment may be as equally fruitful.

\section{SCREENING AND DIAGNOSIS}

HCC is the main cause of death in patients with cirrhosis, and long-term disease-free survival will rely on its early detection and treatment ${ }^{1-3}$. Since the population at risk is identified, all scientific associations recommend regular ultrasound (US) screening in at-risk patients if they would be treated if diagnosed with HCC. This limits screening to patients with preserved liver function (Child-Pugh A and B) and absence of severe comorbidities. Diagnostic work-up should be initiated when detected nodules reach $10 \mathrm{~mm}$. $\alpha$-Fetoprotein (AFP) and other tumour markers do not have clinical value for screening and diagnosis, and novel biomarkers for early HCC are needed, ${ }^{1-3}$ as this surely would improve the current effectiveness of screening. ${ }^{50}$

Biopsy has false-negative results (up to $40 \%$ in HCC $\leq 2 \mathrm{~cm})^{51} \quad 52$ even if applying specific immunostaining approaches, ${ }^{53} 54$ and HCC diagnosis is highly likely in nodules $>10 \mathrm{~mm}$ within a cirrhotic liver. This has been key to develop imaging diagnostic criteria. HCC diagnosis is accepted if intense arterial contrast uptake followed by contrast 'washout' in the delayed venous phase is observed either at MR or CT in a nodule $>10 \mathrm{~mm}$ within a cirrhotic liver. ${ }^{1-3} 55$ This profile has been validated but still has a limited sensitivity, ${ }^{52}$ and current research aims to develop novel imaging technologies ${ }^{56}$ or liverspecific contrasts ${ }^{57}$ that would permit diagnosis for those without the specific findings. Diagnostic needs for clinical practice should be separated from the valued tissue banking for research purposes that should take into account the potential risk of seeding. ${ }^{58}$

\section{OUTCOME PREDICTION}

Patients and relatives expect information about life expectancy. Survival prediction considers tumour burden, liver function and cancer-related symptoms (eg, performance status (PS), Karnofsky Index) and the impact of treatment. Several instruments have been proposed, but the Barcelona Clinic Liver Cancer (BCLC) has been widely endorsed and used for practice and research (figure 2). It links staging with prognosis and firstline treatment option for each. ${ }^{159}$ Patients with very early or early-stage HCC (BCLC A) solitary HCC without vascular invasion should be considered for resection, transplantation or ablation. Size is not a limiting factor for surgery as if the HCC has grown up to large size without spreading and has not induced symptoms, resection may still be beneficial. ${ }^{159}$ BCLC B patients include asymptomatic patients with multifocal HCC without vascular invasion and/or extrahepatic spread. Liver function has 
Figure 2 Barcelona Clinic Liver Cancer strategy for diagnosis and staging at 2012 (1). Patients are stratified into different stages according to tumour burden, liver function and physical status. Each stage is linked to the first-line treatment option that is proposed according to the available scientific evidence. It has to be stressed that the strategy applies for patients evaluated for hepatocellular carcinoma (HCC) and not for end-stage liver cirrhosis. If this is the case, patients should be evaluated for liver transplant and HCC diagnosis could merely become a contraindication if the enlisting criteria are exceeded. If transplant is not feasible, short-term prognosis is poor and HCC treatment will be of no benefit.
BCLC Staging and Treatment Strategy

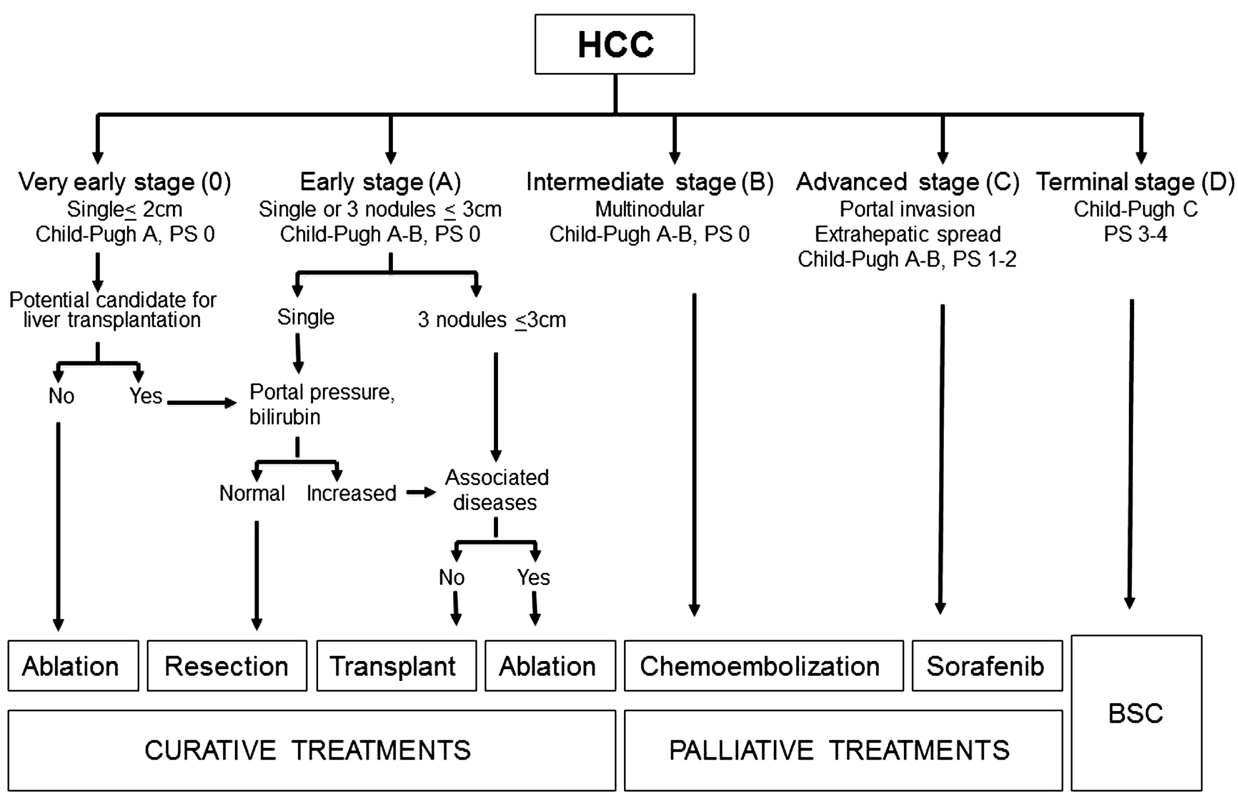

to be preserved and first-line treatment is trans-arterial chemoembolisation (TACE). This should be preferably limited to patients with compensated cirrhosis as treatment may further aggravate cirrhosis if already decompensated. Theoretically, the intermediate BCLC B stage includes a heterogeneous group of disease presentations. However, it is important to remark that the BCLC is devised for patients who do not present major liver function impairment that would have to be considered for transplantation in the absence of severe comorbidities and if they would not have excessive tumour burden (figure 1). The Child-Pugh classification ${ }^{60}$ is commonly used to evaluate liver function and life expectancy, but this is not fully served by it or by the MELD score. ${ }^{61}$ Therefore, spontaneous bacterial peritonitis, refractory ascites, hyponatremia, episodes of encephalopathy among several other parameters indicate end-stage cirrhosis. $^{62}$ Thus, even if patients would fit into Child-Pugh B, an expert hepatologist evaluation would classify such patients as presenting end-stage liver cirrhosis (becoming indeed a BCLC D) and disregard any anticancer therapy. Same heterogeneity affects the extent of tumour burden, but careful clinical assessment in multifocal HCC affecting both lobes usually discloses cancer-related symptoms and then patients should be classified as BCLC C. This stage also includes those with extrahepatic spread and/or vascular invasion. They will benefit from sorafenib therapy. Finally, end-stage patients (BCLC D) are at the end of the clinical spectrum and their dismal prognosis can be easily predicted by markedly impaired PS or end-stage cirrhosis. In such patients, HCC diagnosis may merely become a contraindication for transplantation.

Biomarkers such as AFP, VEGF, angiopoietin-2 or c-Kit may allow further prognostic stratification. ${ }^{63}$ Increased AFP is associated with higher risk of progression while waiting for transplant $^{64} 65$ and poorer prognosis at intermediate or advanced stage HCC. ${ }^{63} 66$ Thus, while treatment is not modified according to AFP, research trials may use these parameters for stratification prior to randomisation. Tissue biomarkers such as keratin $19^{67}$ that would be predictive of more aggressive disease would also be of major help if properly validated. Timing and pattern of progression impact survival after treatment ${ }^{68}$ and should also be taken into account in outcome prediction.

\section{TREATMENT: CURRENT CHALLENGES AND FUTURE PERSPECTIVES}

The endpoint of treatment is to improve survival with quality-of-life preservation. Technical feasibility is not a surrogate for improved survival, and therapeutic recommendation has to be driven by evidence-based, risk-benefit analysis.

The development of locoregional procedures (ablation, chemo/radio embolisation) that may induce tumour necrosis and positively impact survival, and the efficacy of sorafenib for patients at advanced stage have altered the old limited therapeutic landscape. Treatment indications and applications have been refined, and if patients are not candidates for first-line therapy as per stage, they can be shifted to the treatment option for a more progressed BCLC stage (the treatment stage migration concept). ${ }^{13}$ Treatment of HCC in a non-cirrhotic liver follows the same principles, although efficacy and impact on outcome are less predictable.

\section{Open issues in surgical management of HCC in the era of liver transplantation}

In conventional descriptions, hepatic resection and liver transplantation (LT) are often presented as separate components of the so-called 'surgical' HCC: a disputed definition that lacks a specific clinical designation. ${ }^{1} 69$ The results of resection and transplantation are difficult to summarise since not a single surgical modality may fit all HCC presentations, being individual components of the patients crucial for decision making. Resection and transplantation achieve the best outcomes in wellselected candidates (5-year survival of 60-80\%) and compete as the first option in patients with early tumours and wellpreserved liver function on an intention-to-treat (ITT) analysis. ${ }^{2} 3$ Currently the following four concepts need to be addressed.

\section{Current decision making in LT}

Both in America and in Europe the number of patients waiting for a liver exceeds the number of performed transplants per year; less than one patient out of three of those enlisted receives $\mathrm{LT}^{70}$ The introduction of living-related LT and the use of marginal cadaveric donors and non-heart beating donors have not significantly modified this trend. 
Decision making regarding LT for cancer versus non-cancer patients is also confounded by the progressive increase in the number of HCC patients. ${ }^{71}$ After the implementation of the Milan Criteria (MC), ${ }^{72}$ the number of LTs for HCC has increased worldwide and currently in Europe about 27\% of all LT patients have HCC with countries peaking over $40 \% .^{73}$ Thus, major emphasis has been placed on policies and priorities regarding waiting list management (table 1). ${ }^{74-77}$ The MELD score accurately predicts poor short-term outcome in cirrhosis and it allows priority policies to transplant the sickest. Conversely, the heterogeneity of tumour presentation and the variability of response to treatments impede an accurate prediction of progression, effective transplantation and survival after transplantation in HCC patients. Complex statistical models have been advocated, but the controversies persist and no strategy has been uniformly adopted (table 2).

\section{Transplant selection criteria for HCC}

The criteria for determining whether a HCC patient is eligible for LT are very heterogeneous worldwide. However, the MC remain the benchmark for patient selection and the baseline comparator with other suggested criteria ${ }^{78}$ (Table 3). Meta-analysis of published data has confirmed the strong association of MC (single HCC $\leq 5 \mathrm{~cm}$ or multiple HCC $\leq 3$ nodules $\leq 3 \mathrm{~cm}$, with no macro-vascular invasion on radiographic staging) with a survival advantage (HR 1.7) and a low risk of selecting an aggressive biologic behaviour with respect to patients exceeding them. ${ }^{79}$ Nevertheless, MC are often referred to as restrictive and 'expanded criteria' have been proposed. The University of San Francisco (UCSF) criteria have been partially validated, but they significantly overlap with $\mathrm{MC}$ and at best would just expand candidates for LT $\approx 5 \% .{ }^{80}$ A study of more than 1500 tumour explants from patients undergoing LT beyond MC reported that patient prognostication may be individualised according to a specific algorithm (http://www. hcc-olt-metroticket.org/calculator): the larger the tumour burden is, the lower is the post-transplant expected survival. Post-LT outcome can be calculated as a continuous function contouring different combinations of tumour size and number that compete for the same survival. ${ }^{81}$ Accordingly, patients with tumours within the 'up-to-seven' rule without microvascular invasion at explant achieve competitive outcomes with respect to conventional criteria. This 'up-to-seven' pathology proposal has been externally validated ${ }^{81-83}$ but requires prospective validation studies using pretransplant radiology. ${ }^{3}$

Table 1 Specificities of hepatocellular carcinoma (HCC) in cirrhosis with respect to cirrhosis lacking $\mathrm{HCC}$ at the time of transplant consideration

\begin{tabular}{|c|c|}
\hline Cirrhosis & HCC+cirrhosis \\
\hline High pretransplant mortality & Low pretransplant mortality \\
\hline $\begin{array}{l}\text { High post-transplant long-term } \\
\text { recovery }\end{array}$ & $\begin{array}{l}\text { Variable post-transplant cure, depending } \\
\text { on tumour stage at operation }\end{array}$ \\
\hline $\begin{array}{l}\text { Predictable outcome with no } \\
\text { transplant through the MELD score }\end{array}$ & $\begin{array}{l}\text { Composite prognostic factors and } \\
\text { variable biology influencing outcome }\end{array}$ \\
\hline $\begin{array}{l}\text { No competitive options beside } \\
\text { transplantation }\end{array}$ & $\begin{array}{l}\text { Competitive options in selected patients } \\
\text { subgroups }\end{array}$ \\
\hline Urgency principle & Utility principle \\
\hline
\end{tabular}

Patient drop-out on the waiting list due to HCC progression is problematic. HCC may progress while waiting for an organ and this impairs the intention to treat results. Resection, ablation, transarterial embolisation and transarterial radiation are commonly used to bridge patients to transplant with avoidance of unacceptable progression, but robust evidence of effectiveness is lacking. $^{2} 38$ The risk of exclusion is battled through priority policies, but reasons for drop-out in non-tumour patients (ie, uncontrolled liver failure or death) widely differ from those usually linked to drop-out in case of HCC (ie, tumour progression and inefficacy of treatments). ${ }^{71}$ Again, a perfect equitable approach for all enlisted patients is not yet available.

Excessive priority for HCC with respect to non-tumour indications would result in increased post-transplant tumour recurrences. To better balance pretransplant and post-transplant expectations, standardised criteria for enlisting or delisting HCC patients and identification of those patients at a high risk of drop-out are a priority. In this respect AFP has shown significant prognostic potential. In a large French multicentric study, the AFP inclusion in a prognostic score model of post-LT outcome has improved the predictive performance of MC. ${ }^{65} \mathrm{~A}$ similar improvement in selection criteria has been identified for AFP (especially $>400 \mathrm{ng} / \mathrm{mL}$ ) when combined with total tumour volume (TTV) rather than tumour size-and-number characteristics, ${ }^{84}$ with $115 \mathrm{~cm}^{3}$ being the TTV cut-off found compliant with a good post-LT prognosis (table 3). In general, HCC patients on the waiting list with baseline serum level of AFP $>200 \mathrm{ng} / \mathrm{mL}$ display significantly worse outcomes, although the most significant adverse determinant is the steady increase of AFP $>15 \mathrm{ng} / \mathrm{mL} / \mathrm{month}^{85}$ Interestingly, AFP cut-offs of 300 , 400 and $1000 \mathrm{ng} / \mathrm{mL}$ have been suggested as delisting indicators. ${ }^{86-89}$ Nevertheless, these statistical calculations are difficult to apply to an individual patient.

Any future expansion of criteria should maintain an overall survival of $\geq 50 \%$ at 5 years. ${ }^{80}$ However, any increase in candidates for LT will enhance the need for organs, lengthen waiting periods, increase drop-out rates and impair outcome on an ITT analysis, which is why significant criteria expansions with diversion of donated organ to the poor prognosis patients group should be avoided. Clearly, if the shortage of organs will become less oppressive-as a result of increased donation rate or considering the reduced impact of current candidates with $\mathrm{HCV}$ cirrhosis, better served in the near future by more effective antiviral drugs- the potential expansion of criteria for HCC will not impact the access to transplant of the optimal cancer candidates and not affect the non-cancer patients categories.

Table 2 Allocation models considered for liver transplantation

Model Definition

Urgency Focused on pretransplant risk of dying: patients with worse outcome on the waiting list are given higher priority for transplantation (based on Child-Pugh or MELD score)

Utility Based on maximisation of post-transplant outcome, takes into account donor and recipient characteristics: mainly used for HCC since the MELD score poorly predicts post-transplant outcome in HCC due to the absence of donor factors and lack of predicting tumour progression while waiting

Benefit Calculated by subtracting to the survival achieved with LT the survival obtained without LT. Ranks patients according to the net survival benefit that they would derive from transplantation and maximise the lifetime gained through transplantation. If applied to HCC without adjustments, it may prioritise patients at highest risk or recurrence.

HCC, hepatocellular carcinoma; LT, liver transplantation. 
Table 3 Selection criteria in liver transplantation for HCC*

\begin{tabular}{|c|c|c|}
\hline Criteria & Definition & Features \\
\hline Milan (MC) & $\begin{array}{l}\text { Single lesion } \leq 5 \mathrm{~cm} \\
\text { Up to } 3 \text { lesions } \leq 3 \mathrm{~cm} \\
\text { No macrovascular invasion }\end{array}$ & $\begin{array}{l}\text { The benchmark of patient selection criteria in patients undergoing LT for HCC endorsed in } \\
\text { major international guidelines }\end{array}$ \\
\hline UCSF & $\begin{array}{l}\text { Single } \leq 6.5 \mathrm{~cm} \\
\text { Up to three lesions } \leq 4.5 \mathrm{~cm} \\
\text { Sum of tumour diameter } \leq 8 \mathrm{~cm}\end{array}$ & $\begin{array}{l}\text { Significant overlap with MC allowing at best the expansion of LT candidate with HCC of around } \\
5 \%\end{array}$ \\
\hline Up-to-7 & $\begin{array}{l}\text { Sum of size }(\mathrm{cm}) \text { and number of } \mathrm{HCC} \text { nodules } \leq 7 \\
\text { No } \mathrm{mVI}\end{array}$ & $\begin{array}{l}\text { Flexible approach allowing patients with different size-and-number combinations to compete } \\
\text { for the same survival. Online calculator at http://hcc-olt-metroticket.org/calculator }\end{array}$ \\
\hline TTV+AFP & $\begin{array}{l}\text { Any lesions up to TTV } \leq 115 \mathrm{~cm}^{3} \\
\text { AFP } \leq 400 \mathrm{ng} / \mathrm{mL}\end{array}$ & $\begin{array}{l}\text { Combined score would exclude large HCC or small one with potentially aggressive behaviour } \\
\text { and poor post-LT outcomes }\end{array}$ \\
\hline Milan+AFP & $\begin{array}{l}\text { Score system based Number of nodules Size of the largest } \\
\text { nodule AFP at listing }(<100 ; 100-1000 ;>1000 \mathrm{ng} / \mathrm{mL})\end{array}$ & $\begin{array}{l}\text { Within MC, score } \leq 2 \text { predicts good survival. Patients exceeding MC with AFP }<100 ; \leq 3 \\
\text { nodules; } \leq 6 \mathrm{~cm} \text { might be considered eligible for LT }\end{array}$ \\
\hline
\end{tabular}

\section{Pretransplant HCC downstaging: true benefit or just another selection tool?}

The term 'downstaging' defines the reduction of the HCC burden to meet acceptable criteria for $\mathrm{LT}^{90}$ ' acceptable' criteria being defined by expected survival after $\mathrm{LT}^{88}$ that is equal to those patients who meet transplant criteria without downstaging. ${ }^{78} 90$ Such intricate definition reflects the undetermined benefit of downstaging while denotes the principle of the strategy: to select a more favourable tumour 'biology' determined by response to treatment ${ }^{90}$

TACE is the treatment modality most applied for downstaging, followed by radiofrequency ablation (RFA), radioembolisation and surgical resection. Most programmes use the MC as the endpoint of downstaging to be maintained for at least 3-6 months. ${ }^{86} 90$ The lack of a reproducible and validated approach for baseline staging, assessment of downstaging, delisting criteria and absence of robust ITT analysis has prevented the endorsement of such approach in guidelines. ${ }^{71}$

\section{Treatment of the very early HCC}

Over the last decade several competitors have challenged transplantation and resection as the most efficacious treatment for early HCC. Considering the competitive long-term results of non-transplant treatment in patients with well-compensated cirrhosis and very early HCC (single tumour of $<2 \mathrm{~cm}$ in size; T1 stage $^{9192}$ ), the application of LT at very early stages of HCC development-usually detected in the setting of screening- may be futile. ${ }^{88}$ Very early tumours can remain dormant for a significant period of time, ${ }^{93} 94$ and their doubling time may exceed 10-20 months. ${ }^{95}$ Not surprisingly, resection and ablation have achieved excellent survival outcomes in this setting, in the range of $60-70 \%$ at 5 years. $^{96} 97$ While a robust trial appropriately comparing LR and ablation is still not available, ${ }^{98}$ large case-control series and modelling studies support RFA as a noninferior $^{99}$ and more cost-effective ${ }^{100}$ treatment for very early HCCs.

For small tumours when all three modalities (ablation, resection and LT) could we applied, there are few data to guide decision making. Pattern of recurrence, patient conditions, liver status and treatments applicability are crucial when the transplant alternative is considered. Proposals include 'ablate and wait' strategy that reserves LT for those patients who develop recurrence $^{100}$ while others have proposed resection as first approach and reserving LT for those patients with microvascular invasion at explant pathology. ${ }^{101}$ Sufficient data to robustly guide decision making are lacking, and trials tailored for all the clinical permutations are not in place.

\section{Post-transplantation follow-up and treatment upon recurrence}

There is no evidence-based recommendation to be applied after transplantation in order to promptly detect and treat HCC recurrence. Early recurrence due to dissemination is likely to have poorer prognosis than late recurrence as it happens after resection, and treatment decision should be individualised according to the same parameters as at first diagnosis. Tumour seeding due to tumour puncture for diagnosis or ablation can be successfully resected with potential long-term disease-free survival. Retrospective studies have shown that surgical removal of recurrence, when feasible, is beneficial and recent reports did show a non-toxic, positive effect of sorafenib treatment from the time of post-transplant HCC-untreatable progression with respect to historic controls. ${ }^{102}$ To which extent any treatment approach results in improved survival is unknown.

\section{Locoregional treatment}

Locoregional options aim to induce tumour necrosis, and this has primed a refinement of the conventional oncology criteria to evaluate treatment activity. The RECIST criteria ${ }^{103}$ are not informative as necrosis may not be paralleled by tumour burden reduction. In ablation the goal is to achieve complete response recognised by the absence of tumour contrast uptake by contrast enhanced US, CT or MRI. ${ }^{3} 104$ By contrast, TACE seldom achieves complete response and the magnitude of response takes into account the presence of residual viable tumour tissue. The degree of lipiodol (an oily contrast used to produce an emulsion with chemotherapy, ie, injected prior to arterial obstruction with gelfoam in conventional TACE) accumulation in the tumour is not accurate to reflect necrosis. ${ }^{105}$ EASL criteria and its follow-up development known as RRECIST $^{106}$ take into account the degree of tumour necrosis as manifested by dynamic CT or MRI. ${ }^{106}$ Extent of tumour necrosis has been correlated with outcome after ablation or TACE. ${ }^{107-109}$ Complete necrosis after ablation offers no controversy, but quantification of partial necrosis in patients with multifocal disease is quite challenging and this is far more complex in patients under systemic therapy (figure 3), there also being a major need to proof interobserver agreement. 


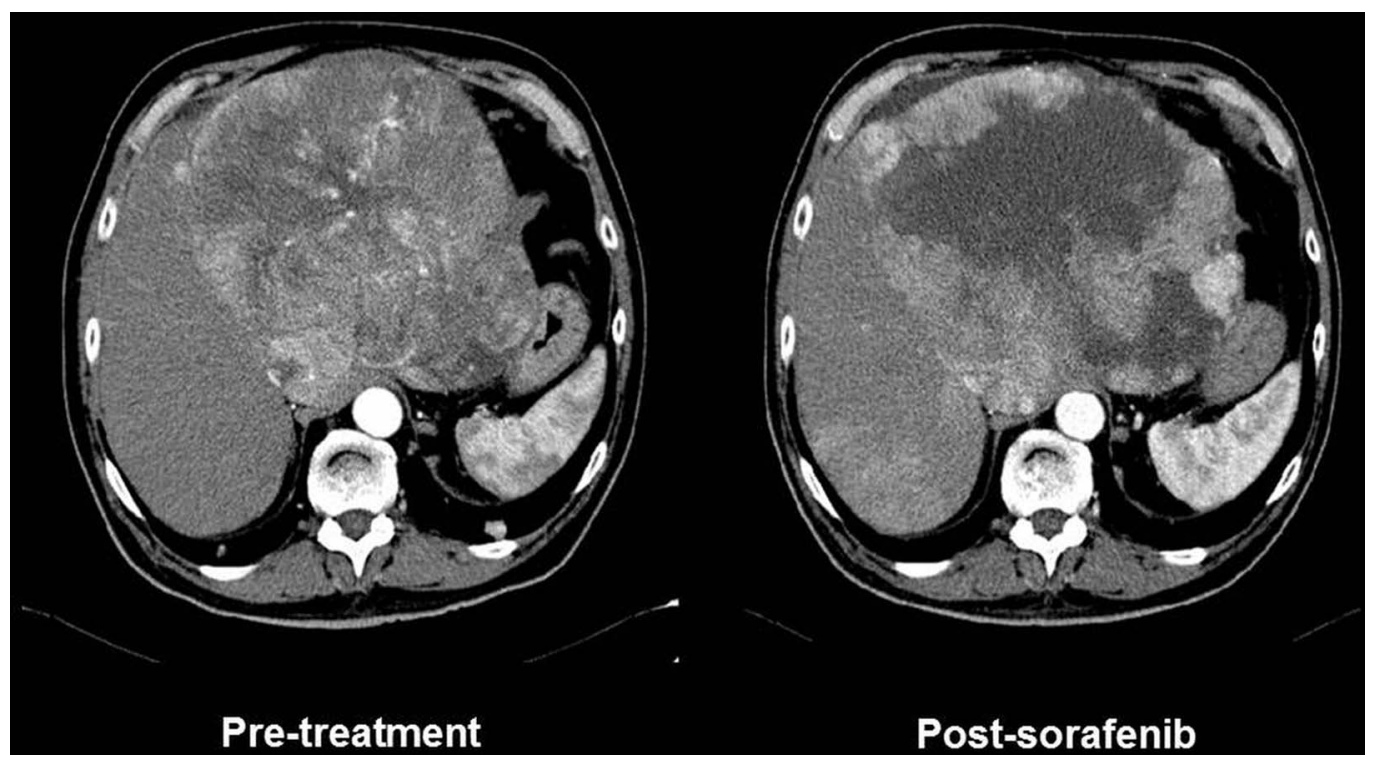

Figure 3 CT of a large heterogeneous hepatocellular carcinoma treated with sorafenib. The tumour is recognised as a large hypervascular mass with heterogeneous intensity of contrast uptake (left panel). Sorafenib treatment induces a reduction in vascular supply and an area of necrosis that is reflected by absence of contrast enhancement. This reduction of tumour burden is not captured by conventional RECIST and thus novel proposals to register necrosis induction have been developed and known as EASL or mRECIST criteria. Their correlation with treatment efficacy and improved outcome has been validated for ablation and chemoembolisation, but robust validation in patients treated with sorafenib or other systemic agents is lacking. Indeed, the heterogeneity of the changes and the varying pattern in different foci may prevent a robust assessment with adequate interobserver agreement. Hence, use of the registered information to attempt correlation of changes at imaging and outcome is challenging.

\section{Ablation}

Radiofrequency (RFA) is now the first-line technique for ablation. ${ }^{110}$ Ethanol injection has less local control efficacy ${ }^{111}$ but still has a role to achieve complete response when the residual viable tissue is minimal or when the location of the tumour implies risk of adverse events. Both techniques achieve the same effectiveness and survival in solitary HCC $\leq 2 \mathrm{~cm} .{ }^{112} 113$ Survival of patients with $\mathrm{HCC}<3 \mathrm{~cm}$ treated by ablation competes with that of surgical candidates. ${ }^{112} 113$ Hence, both approaches may be considered as first line and consideration has to be given to age/ associated comorbidities and location of the tumour. In HCC $>3 \mathrm{~cm}$, the failure rate increases and the same applies to multifocal HCC even if tumour size is less than $3 \mathrm{~cm} .{ }^{112}{ }^{113}$ In such instance, resection or the combined treatment by chemoembolisation and ablation has been suggested to improve survival, ${ }^{110} 114$ but available studies preclude robust conclusions because of suboptimal patient selection. Trials targeting the population to benefit from the combined approach are still awaited. Recurrence after ablation is the same as after surgical resection, although anatomic resection may achieve better local control. Unfortunately, there is no effective approach to reduce risk of recurrence. Antiviral treatment may reduce the rate of metachronic $\mathrm{HCC}$ in $\mathrm{HBV}$ patients. ${ }^{1-3}$

\section{Transarterial chemoembolisation and transarterial} radioembolisation (TARE)

The dominant arterial vascular supply of HCC provides the rationale to treat these cancers through selective delivery of anticancer agents. TACE combines selective arterial obstruction with chemotherapy injection. Cumulative meta-analysis of the informative trials has positioned TACE as the first-line option for BCLC B patients. ${ }^{107}$ Restrictive selection of candidates to exclude those with decompensated cirrhosis, proper techniques and an adequate policy to stop TACE at the time of liver failure or lack of treatment response results in median survival exceeding 4 years. ${ }^{115} 116$ This figure provides a benchmark to be used when debating the benefits of surgery in patients with multifocal disease or transplantation with expanded criteria. Tolerance to the procedure has improved by the use of drug-eluting beads that obstruct arterial vessels and slowly release chemotherapy. ${ }^{117}$ This enhances exposure of tumour cells to the agent and reduces systemic levels responsible for haematological adverse events.

Since arterial obstruction induces release of angiogenic factors, it makes sense to combine TACE with antiangiogenics such as sorafenib. While the combination is safe, its efficacy in enhancing tumour response and/or delaying tumour progression rate has not been proven. ${ }^{118} 119$ Indeed, the best sequence of combining sorafenib and TACE is not defined.

TARE differs from TACE. It does not base its effect in arterial obstruction but rather in the local action of $\beta$ radiation through the lodging of yttrium-loaded glass or resin spheres in vessels feeding the tumour. ${ }^{120}$ The procedure is well tolerated, and cohort studies with heterogeneous populations suggest it may provide survival rates similar to TACE and sorafenib, particularly in the setting of portal vein thrombosis (PVT) ${ }^{121} 122$. Ongoing randomised controlled trials (RCTs) in first-line combined or head to head versus sorafenib or in second-line versus placebo will define the population that benefits from this approach.

\section{Systemic therapy and endpoints reconsideration in HCC}

No systemic agent had been shown to improve patient survival until the advent of sorafenib, an oral multikinase inhibitor with antiangiogenic and antiproliferative action. Two RCTs demonstrated a significant $30 \%$ improvement in survival with an adequate safety profile. ${ }^{123} 124$ The success of sorafenib altered several tenets relative to cancer therapy. It proved that survival of cancer patients may be improved in the absence of a decrease 


\begin{tabular}{lll} 
Diagnosis 1st Treat. & $\begin{array}{l}\text { Recurrence/ } \\
\text { Progression }\end{array}$ & Death \\
Survival after diagnosis & \\
\hline
\end{tabular}

Survival after 1st treatment

$$
\text { Survival after progression (PPS) }
$$

Figure 4 Survival data starting follow-up at different time points. It is common to describe survival after the indication of the first treatment or when recurrence or progression are registered. In most studies, the staging of the patients just takes into account the tumour burden, liver function and physical status at the time of evaluation, while the time and events between diagnosis and first treatment, and the timing and pattern of recurrence/progression is usually dismissed. This may intensely flaw the prognostic evaluation of the patients and prevent a proper design and evaluation of therapeutic interventions.

in tumour burden according to conventional RECIST. ${ }^{123}$ It reinforced the value of time-to-progression (TTP) as a more valuable signal of efficacy, and questioned interrupting therapy due to mere radiology progression. However, the halting of tumour progression is limited in time and it is not uniform. There is an urgent need to identify biomarkers and develop functional imaging techniques that would predict who responds best or when efficacy is lost. As mentioned above, the mRECIST proposal to assess necrosis (if existing) and TTP to estimate treatment activity as a surrogate of efficacy needs extensive validation in prospective trials. Indeed, the fact that treatment is associated with changes in imaging pattern does not directly translate into a survival advantage. TTP is informative but it sure needs to be refined as not all tumour progressions at imaging translate into an impaired survival. ${ }^{68}$ In the RCT, assessing brivanib versus placebo in second line after sorafenib failure/intolerance TTP was significantly improved, but survival was not. ${ }^{125}$ The clinically appealing progression-free survival (PFS) may also be misleading as shown in the sunitinib versus sorafenib trial: PFS was similar, but survival was worse for sunitinib. ${ }^{126}$ If tumour burden reduction is not the goal and TTP and PFS are not reliable, novel tools to identify efficacy of new agents at early phases of development are needed. Most of the data we use today for survival prediction after any intervention (from surgery to systemic therapy) are based on studies in which time zero corresponds to the date of the specific intervention. Proper analysis of the timing and nature of the previous evolutionary events in HCC patients prior to entering any therapeutic intervention has not been explored (figure 4). Pattern of recurrence after surgery is well known to have an impact in survival, ${ }^{127}$ but the impact of progression pattern in survival has just been recognised ${ }^{68}$ and hence this should be taken into account in practice and research.

So far, none of the agents or combinations have exceeded the benefits of sorafenib. Phase 3 trials testing sunitinib, linifanib, brivanib or the combination of sorafenib with erlotinib have been negative, ${ }^{126}{ }^{128-130}$ as well as all agents tested in second line ${ }^{125} 131$. Efficacy of the combination of sorafenib with chemotherapy or novel approaches trying to enrich the trials according to molecular profile is ongoing. The recognition that patients with high c-met expression treated with tivantinib present a better outcome than those with low/absent c-met expression ${ }^{132}$ has offered the background to run a large phase 3 trial in second line. Results of all these endeavours are eagerly awaited as well as the final incorporation of immune cancer control as a potential therapeutic option. ${ }^{133} 134$
In summary, major changes have occurred in the diagnosis and management of HCC. Hopefully, prevention plans to reduce the impact of risk factors, an earlier diagnosis and more effective therapies will finally induce a major reduction of liver cancer-related death and eliminate HCC from the top position of cancer killers.

Contributors The manuscript has three different parts about molecular profiling (taken care by GJG), transplantation and surgery (taken care by VM) and diagnosis and non-surgical treatment (taken care by JB).

Competing interests $J B$ declares conflicts of interest due to consultancy/research studies with Abbott, Arqule, Bayer Shering Pharma, BTG Biocompatibles, BMS, Glaxo-Welcome, Imclone, Kowa, Lilly, Novartis, OSI, Shering-Plough (Merck) and Terumo. GJG declares conflicts of interest due to consultancy with Bayer, Bristol-Meyers Squibb, Chugai, Daiichi Sanyo, Delcath, Genentech, and Generon. VM declares conflict of interest due to consultancy with Bayer and BTG Biocompatibles. JB is supported by a grant of the Instituto de Salud Carlos III (PI11/01830). CIBERehd is funded by Instituto de Salud Carlos III. GJG is supported by grant DK59427 from the National Institutes of Health and the Mayo Clinic. VM is partially supported by grants of the Italian Association for Cancer Research (AIRC), the Ministry of Health: finalised cancer research and the National Transplant Centre (CNT).

Provenance and peer review Commissioned; externally peer reviewed.

\section{REFERENCES}

1 Forner A, Llovet JM, Bruix J. Hepatocellular carcinoma. Lancet 2012;379:1245-55.

2 Bruix J, Sherman M. Management of hepatocellular carcinoma: an update. Hepatology 2011;53:1020-2.

3 EASL-EORTC clinical practice guidelines: management of hepatocellular carcinoma. J Hepatol 2012;56:908-43.

4 Lai $C L$, Yuen MF. Prevention of hepatitis B virus-related hepatocellular carcinoma with antiviral therapy. Hepatology 2013;57:399-408.

5 Singh S, Singh PP, Singh AG, et al. Anti-diabetic medications and the risk of hepatocellular cancer: a systematic review and meta-analysis. Am J Gastroenterol 2013;108:881-91; quiz 92.

6 Singh S, Singh PP, Singh AG, et al. Statins are associated with a reduced risk of hepatocellular cancer: a systematic review and meta-analysis. Gastroenterology 2013;144:323-32.

7 Saito T, Chiba T, Yuki K, et al. Metformin, a diabetes drug, eliminates tumor-initiating hepatocellular carcinoma cells. PLOS ONE 2013;8: e70010.

8 Zheng L, Yang W, Wu F, et al. Prognostic Significance of AMPK Activation and Therapeutic Effects of Metformin in Hepatocellular Carcinoma. Clin Cancer Res 2013:19:5372-80.

9 Nkontchou G, Aout M, Mahmoudi A, et al. Effect of long-term propranolol treatment on hepatocellular carcinoma incidence in patients with $\mathrm{HCV}$-associated cirrhosis. Cancer Prev Res (Phila) 2012;5:1007-14

10 Hoshida Y, Nijman SM, Kobayashi M, et al. Integrative transcriptome analysis reveals common molecular subclasses of human hepatocellular carcinoma. Cancer Res 2009;69:7385-92.

11 Hoshida Y, Toffanin S, Lachenmayer A, et al. Molecular classification and novel targets in hepatocellular carcinoma: recent advancements. Semin Liver Dis 2010;30:35-51.

12 Minguez B, Hoshida Y, Villanueva A, et al. Gene-expression signature of vascular invasion in hepatocellular carcinoma. J Hepatol 2011;55:1325-31.

13 Navin N, Kendall J, Troge J, et al. Tumour evolution inferred by single-cell sequencing. Nature 2011;472:90-4.

14 Yachida S, Jones S, Bozic I, et al. Distant metastasis occurs late during the genetic evolution of pancreatic cancer. Nature 2010;467:1114-17.

15 Yap TA, Gerlinger M, Futreal PA, et al. Intratumor heterogeneity: seeing the wood for the trees. Sci Trans/ Med 2012;4:127ps10.

16 Tao Y, Ruan J, Yeh SH, et al. Rapid growth of a hepatocellular carcinoma and the driving mutations revealed by cell-population genetic analysis of whole-genome data. Proc Natl Acad Sci USA 2011;108:12042-7.

17 Piccirillo SG, Combi R, Cajola L, et al. Distinct pools of cancer stem-like cells coexist within human glioblastomas and display different tumorigenicity and independent genomic evolution. Oncogene 2009;28:1807-11.

18 Sharma SV, Settleman J. Oncogene addiction: setting the stage for molecularly targeted cancer therapy. Genes Dev 2007;21:3214-31.

19 Chapman PB, Hauschild A, Robert C, et al. Improved survival with vemurafenib in melanoma with BRAF V600E mutation. N Engl J Med 2011;364:2507-16.

20 Straussman R, Morikawa T, Shee K, et al. Tumour micro-environment elicits innate resistance to RAF inhibitors through HGF secretion. Nature 2012;487:500-4.

21 Wilson TR, Fridlyand J, Yan Y, et al. Widespread potential for growth-factor-driven resistance to anticancer kinase inhibitors. Nature 2012:487:505-9. 
22 Casper M, Grunhage F, Lammert F. Cancer risk in chronic hepatitis B: do genome-wide association studies hit the mark? Hepatology 2011;53:1390-2.

23 Chan KY, Wong CM, Kwan JS, et al. Genome-wide association study of hepatocellular carcinoma in Southern Chinese patients with chronic hepatitis B virus infection. PLOS ONE 2011;6:e28798.

24 Clifford RJ, Zhang J, Meerzaman DM, et al. Genetic variations at loci involved in the immune response are risk factors for hepatocellular carcinoma. Hepatology 2010;52:2034-43.

25 Estrabaud E, Vidaud M, Marcellin P, et al. Genomics and HCV infection: progression of fibrosis and treatment response. J Hepatol 2012;57:1110-25.

26 Hoshida Y, Fuchs BC, Tanabe KK. Genomic risk of hepatitis C-related hepatocellular carcinoma. J Hepatol 2012;56:729-30.

27 Kumar V, Kato N, Urabe Y, et al. Genome-wide association study identifies a susceptibility locus for HCV-induced hepatocellular carcinoma. Nat Genet 2011:43:455-8

28 Li S, Qian J, Yang Y, et al. GWAS identifies novel susceptibility loci on 6p21.32 and 21q21.3 for hepatocellular carcinoma in chronic hepatitis B virus carriers. PLoS Genet 2012:8:e1002791.

29 Nahon P, Zucman-Rossi J. Single nucleotide polymorphisms and risk of hepatocellular carcinoma in cirrhosis. J Hepatol 2012;57:663-74.

30 Nishida N, Sawai H, Matsuura K, et al. Genome-wide association study confirming association of HLA-DP with protection against chronic hepatitis $B$ and viral clearance in Japanese and Korean. PLOS ONE 2012;7:e39175.

31 Abu Dayyeh BK, Yang M, Fuchs BC, et al. A functional polymorphism in the epidermal growth factor gene is associated with risk for hepatocellular carcinoma. Gastroenterology 2011;141:141-9.

32 Tanabe KK, Lemoine A, Finkelstein DM, et al. Epidermal growth factor gene functional polymorphism and the risk of hepatocellular carcinoma in patients with cirrhosis. JAMA 2008;299:53-60.

33 Nault JC, Mallet M, Pilati C, et al. High frequency of telomerase reverse-transcriptase promoter somatic mutations in hepatocellular carcinoma and preneoplastic lesions. Nat Commun 2013:4:2218.

34 Hoshida Y, Villanueva A, Kobayashi $M$, et al. Gene expression in fixed tissues and outcome in hepatocellular carcinoma. N Engl J Med 2008;359:1995-2004.

35 Naugler WE, Sakurai T, Kim S, et al. Gender disparity in liver cancer due to sex differences in MyD88-dependent IL-6 production. Science 2007;317:121-4.

36 Villanueva A, Hoshida Y, Battiston C, et al. Combining clinical, pathology, and gene expression data to predict recurrence of hepatocellular carcinoma. Gastroenterology 2011;140:1501-12 e2.

37 Nault JC, de Reynies A, Villanueva A, et al. A hepatocellular carcinoma 5-gene score associated with survival of patients following liver resection. Gastroenterology 2013;145:176-87.

38 Villanueva A, Minguez B, Forner A, et al. Hepatocellular carcinoma: novel molecular approaches for diagnosis, prognosis, and therapy. Annu Rev Med 2010:61:317-28.

39 Shen J, Wang S, Zhang YJ, et al. Genome-wide DNA methylation profiles in hepatocellular carcinoma. Hepatology 2012;55:1799-808.

40 Mott JL. MicroRNAs involved in tumor suppressor and oncogene pathways: implications for hepatobiliary neoplasia. Hepatology 2009;50:630-7.

41 Murakami Y, Yasuda T, Saigo K, et al. Comprehensive analysis of microRNA expression patterns in hepatocellular carcinoma and non-tumorous tissues. Oncogene 2006:25:2537-45.

42 Toffanin S, Hoshida Y, Lachenmayer A, et al. MicroRNA-based classification of hepatocellular carcinoma and oncogenic role of miR-517a. Gastroenterology 2011;140:1618-28 e16.

43 Guichard C, Amaddeo G, Imbeaud S, et al. Integrated analysis of somatic mutations and focal copy-number changes identifies key genes and pathways in hepatocellular carcinoma. Nat Genet 2012;44:694-8.

44 Fujimoto A, Totoki Y, Abe T, et al. Whole-genome sequencing of liver cancers identifies etiological influences on mutation patterns and recurrent mutations in chromatin regulators. Nat Genet 2012;44:760-4.

45 Ferber MJ, Montoya DP, Yu C, et al. Integrations of the hepatitis B virus (HBV) and human papillomavirus (HPV) into the human telomerase reverse transcriptase (hTERT) gene in liver and cervical cancers. Oncogene 2003;22:3813-20.

46 Sung WK, Zheng H, Li S, et al. Genome-wide survey of recurrent HBV integration in hepatocellular carcinoma. Nat Genet 2012;44:765-9.

47 Totoki Y, Tatsuno K, Yamamoto S, et al. High-resolution characterization of a hepatocellular carcinoma genome. Nat Genet 2011;43:464-9.

48 Li M, Zhao $H$, Zhang $X$, et al. Inactivating mutations of the chromatin remodeling gene ARID2 in hepatocellular carcinoma. Nat Genet 2011;43:828-9.

49 Dawson MA, Kouzarides T, Huntly BJ. Targeting epigenetic readers in cancer. N Engl J Med 2012;367:647-57.

50 El-Serag HB, Kramer JR, Chen GJ, et al. Effectiveness of AFP and ultrasound tests on hepatocellular carcinoma mortality in HCV-infected patients in the USA. Gut 2011;60:992-7.

51 Caturelli E, Solmi L, Anti M, et al. Ultrasound guided fine needle biopsy of early hepatocellular carcinoma complicating liver cirrhosis: a multicentre study. Gut 2004;53:1356-62.
52 Forner A, Vilana R, Ayuso C, et al. Diagnosis of hepatic nodules $20 \mathrm{~mm}$ or smaller in cirrhosis: prospective validation of the noninvasive diagnostic criteria for hepatocellular carcinoma. Hepatology 2008;47:97-104.

53 Tremosini $S$, Forner A, Boix $L$, et al. Prospective validation of an immunohistochemical panel (glypican 3, heat shock protein 70 and glutamine synthetase) in liver biopsies for diagnosis of very early hepatocellular carcinoma. Gut 2012:61:1481-7.

54 Cai MY, Tong ZT, Zheng F, et al. EZH2 protein: a promising immunomarker for the detection of hepatocellular carcinomas in liver needle biopsies. Gut 2011:60:967-76.

55 Sangiovanni A, Manini MA, lavarone $M$, et al. The diagnostic and economic impact of contrast imaging techniques in the diagnosis of small hepatocellular carcinoma in cirrhosis. Gut 2010;59:638-44.

56 Piana G, Trinquart L, Meskine N, et al. New MR imaging criteria with a diffusion-weighted sequence for the diagnosis of hepatocellular carcinoma in chronic liver diseases. J Hepatol 2011;55:126-32.

57 Choi JW, Lee JM, Kim SJ, et al. Hepatocellular carcinoma: imaging patterns on gadoxetic acid-enhanced MR Images and their value as an imaging biomarker. Radiology 2013;267:776-86.

58 Silva MA, Hegab B, Hyde C, et al. Needle track seeding following biopsy of liver lesions in the diagnosis of hepatocellular cancer: a systematic review and meta-analysis. Gut 2008;57:1592-6.

59 de Lope CR, Tremosini S, Forner A, et al. Management of HCC. J Hepatol 2012;56(Suppl 1):S75-87.

60 Pugh RN, Murray-Lyon IM, Dawson JL, et al. Transection of the oesophagus for bleeding oesophageal varices. Br J Surg 1973;60:646-9.

61 Malinchoc M, Kamath PS, Gordon FD, et al. A model to predict poor survival in patients undergoing transjugular intrahepatic portosystemic shunts. Hepatology 2000:31:864-71.

62 Murray KF, Carithers RL Jr. AASLD practice guidelines: evaluation of the patient for liver transplantation. Hepatology 2005;41:1407-32.

63 Llovet JM, Pena CE, Lathia CD, et al. Plasma biomarkers as predictors of outcome in patients with advanced hepatocellular carcinoma. Clin Cancer Res 2012;18:2290-300.

64 Toso C, Mentha G, Majno P. Selection of patients with hepatocellular carcinoma before liver transplantation: need to combine alpha-fetoprotein with morphology? Hepatobiliary Pancreat Dis Int 2010;9:460-1.

65 Duvoux C, Roudot-Thoraval F, Decaens T, et al. Liver transplantation for hepatocellular carcinoma: a model including alpha-fetoprotein improves the performance of Milan criteria. Gastroenterology 2012;143:986-94 e3; quiz e14-5.

66 Leung TW, Tang AM, Zee B, et al. Construction of the Chinese University Prognostic Index for hepatocellular carcinoma and comparison with the TNM staging system, the Okuda staging system, and the Cancer of the Liver Italian Program staging system: a study based on 926 patients. Cancer 2002;94: 1760-9.

67 Govaere 0, Komuta M, Berkers J, et al. Keratin 19: a key role player in the invasion of human hepatocellular carcinomas. Gut 2014;63:674-85.

68 Reig M, Rimola J, Torres F, et al. Postprogression survival of patients with advanced hepatocellular carcinoma: rationale for second-line trial design. Hepatology 2013;58:2023-31.

69 Mazzaferro V, Chun YS, Poon RT, et al. Liver transplantation for hepatocellular carcinoma. Ann Surg Oncol 2008;15:1001-7.

70 http://srtr.transplant.hrsa.gov/annual_reports/2011/default.aspx (accessed 9 Jun 2013).

71 Navasa M, Bruix J. Multifaceted perspective of the waiting list for liver transplantation: the value of pharmacokinetic models. Hepatology 2010;51:12-15

72 Mazzaferro V, Regalia E, Doci R, et al. Liver transplantation for the treatment of small hepatocellular carcinomas in patients with cirrhosis. N Engl J Med 1996:334:693-9.

73 Adam R, Karam V, Delvart V, et al. Evolution of indications and results of liver transplantation in Europe. A report from the European Liver Transplant Registry (ELTR). J Hepatol 2012;57:675-88.

74 Toso C, Dupuis-Lozeron E, Majno P, et al. A model for dropout assessment of candidates with or without hepatocellular carcinoma on a common liver transplant waiting list. Hepatology 2012;56:149-56.

75 Avolio AW, Cillo U, Salizzoni M, et al. Balancing donor and recipient risk factors in liver transplantation: the value of D-MELD with particular reference to HCV recipients. Am J Transplant 2011:11:2724-36.

76 Avolio AW, Agnes S, Cillo U, et al. http://www.D-MELD.com, the Italian survival calculator to optimize donor to recipient matching and to identify the unsustainable matches in liver transplantation. Transp/ Int 2012;25:294-301.

77 Vitale A, Morales RR, Zanus G, et al. Barcelona Clinic Liver Cancer staging and transplant survival benefit for patients with hepatocellular carcinoma: a multicentre, cohort study. Lancet Oncol 2011;12:654-62.

78 Clavien PA, Lesurtel M, Bossuyt PM, et al. Recommendations for liver transplantation for hepatocellular carcinoma: an international consensus conference report. Lancet Oncol 2012;13:e11-22. 
79 Mazzaferro V, Bhoori S, Sposito C, et al. Milan criteria in liver transplantation for hepatocellular carcinoma: an evidence-based analysis of 15 years of experience. Liver Transpl 2011;17(Suppl 2):S44-57.

80 Prasad KR, Young RS, Burra $P$, et al. Summary of candidate selection and expanded criteria for liver transplantation for hepatocellular carcinoma: a review and consensus statement. Liver Transp/ 2011;17(Suppl 2):S81-9.

81 Mazzaferro V, Llovet JM, Miceli R, et al. Predicting survival after liver transplantation in patients with hepatocellular carcinoma beyond the Milan criteria: a retrospective, exploratory analysis. Lancet Oncol 2009;10:35-43

82 Raj A, McCall J, Gane E. Validation of the "Metroticket" predictor in a cohort of patients transplanted for predominantly HBV-related hepatocellular carcinoma. J Hepatol 2011;55:1063-8.

83 Gugenheim J, Bredt LC, lannelli A, et al. Recurrence after liver transplantation for hepatocellular carcinoma according to up-to-seven criteria. Hepatogastroenterology 2013;60:799-806

84 Toso C, Asthana S, Bigam DL, et al. Reassessing selection criteria prior to liver transplantation for hepatocellular carcinoma utilizing the Scientific Registry of Transplant Recipients database. Hepatology 2009;49:832-8.

85 Vibert E, Azoulay D, Hoti E, et al. Progression of alphafetoprotein before liver transplantation for hepatocellular carcinoma in cirrhotic patients: a critical factor. Am J Transplant 2010;10:129-37.

86 Yao FY, Kerlan RK Jr, Hirose R, et al. Excellent outcome following down-staging of hepatocellular carcinoma prior to liver transplantation: an intention-to-treat analysis. Hepatology 2008;48:819-27.

87 Ravaioli M, Grazi GL, Piscaglia F, et al. Liver transplantation for hepatocellular carcinoma: results of down-staging in patients initially outside the Milan selection criteria. Am J Transplant 2008;8:2547-57.

88 Pomfret EA, Washburn K, Wald C, et al. Report of a national conference on liver allocation in patients with hepatocellular carcinoma in the United States. Liver Transp/ 2010;16:262-78.

89 Toso C, Mentha G, Kneteman NM, et al. The place of downstaging for hepatocellular carcinoma. J Hepatol 2010;52:930-6.

90 Bhoori S, Sposito C, Germini A, et al. The challenges of liver transplantation for hepatocellular carcinoma on cirrhosis. Transpl Int 2010;23:712-22.

91 Vauthey JN, Lauwers GY, Esnaola NF, et al. Simplified staging for hepatocellular carcinoma. J Clin Oncol 2002:20:1527-36.

92 OPTN U, eds. United network for organ sharing. Liver Transplant Candidates with hepatocellular carcinoma (HCC) Policy 3.6.4.4. http://optn.transplant.hrsa.gov/ PoliciesandBylaws2/policies/pdfs/policy_8.pdf (accessed 23 Jun 2013).

93 Barbara L, Benzi G, Gaiani S, et al. Natural history of small untreated hepatocellular carcinoma in cirrhosis: a multivariate analysis of prognostic factors of tumor growth rate and patient survival. Hepatology 1992;16:132-7.

94 Ebara M, Ohto M, Shinagawa T, et al. Natural history of minute hepatocellular carcinoma smaller than three centimeters complicating cirrhosis. A study in 22 patients. Gastroenterology 1986;90:289-98.

95 McCaughan GW. Early hepatocellular carcinoma-is there such a thing as too early? J Hepatol 2013;58:210-11.

96 Livraghi T, Meloni F, Di Stasi M, et al. Sustained complete response and complications rates after radiofrequency ablation of very early hepatocellular carcinoma in cirrhosis: is resection still the treatment of choice? Hepatology 2008;47:82-9.

97 Roayaie S, Obeidat K, Sposito C, et al. Resection of hepatocellular cancer $</=2$ cm: results from two Western centers. Hepatology 2012;57:1426-35.

98 Majno PE, Mentha G, Mazzaferro V. Partial hepatectomy versus radiofrequency ablation for hepatocellular carcinoma: confirming the trial that will never be, and some comments on the indications for liver resection. Hepatology 2010;51:1116-18

99 Cho YK, Kim JK, Kim WT, et al. Hepatic resection versus radiofrequency ablation for very early stage hepatocellular carcinoma: a Markov model analysis. Hepatology 2010;51:1284-90.

100 Roberts JP, Venook A, Kerlan R, et al. Hepatocellular carcinoma: ablate and wait versus rapid transplantation. Liver Transp/ 2010;16:925-9.

101 Sala M, Forner A, Varela M, et al. Prognostic prediction in patients with hepatocellular carcinoma. Semin Liver Dis 2005;25:171-80.

102 Sposito C, Mariani L, Germini A, et al. Comparative efficacy of sorafenib versus best supportive care in recurrent hepatocellular carcinoma after liver transplantation: a case-control study. J Hepatol 2013;59:59-66.

103 Eisenhauer EA, Therasse P, Bogaerts J, et al. New response evaluation criteria in solid tumours: revised RECIST guideline (version 1.1). Eur J Cancer 2009:45:228-47.

104 Llovet JM, Di Bisceglie AM, Bruix J, et al. Design and endpoints of clinical trials in hepatocellular carcinoma. J Nat/ Cancer Inst 2008;100:698-711.

105 Golfieri R, Renzulli M, Mosconi C, et al. Hepatocellular carcinoma responding to superselective transarterial chemoembolization: an issue of nodule dimension? J Vasc Interv Radiol 2013;24:509-17.

106 Lencioni R, Llovet JM. Modified RECIST (mRECIST) assessment for hepatocellular carcinoma. Semin Liver Dis 2010;30:52-60.
107 Llovet JM, Bruix J. Systematic review of randomized trials for unresectable hepatocellular carcinoma: chemoembolization improves survival. Hepatology 2003:37:429-42.

108 Gillmore R, Stuart S, Kirkwood A, et al. EASL and mRECIST responses are independent prognostic factors for survival in hepatocellular cancer patients treated with transarterial embolization. J Hepatol 2011;55:1309-16.

109 Memon K, Kulik L, Lewandowski RJ, et al. Radiographic response to locoregional therapy in hepatocellular carcinoma predicts patient survival times. Gastroenterology 2011;141:526-35, 35 e1-2.

110 Lencioni R. Loco-regional treatment of hepatocellular carcinoma. Hepatology 2010;52:762-73.

111 Lin SM, Lin CJ, Lin CC, et al. Randomised controlled trial comparing percutaneous radiofrequency thermal ablation, percutaneous ethanol injection, and percutaneous acetic acid injection to treat hepatocellular carcinoma of $3 \mathrm{~cm}$ or less. Gut 2005; 54:1151-6.

112 Cho YK, Kim JK, Kim MY, et al. Systematic review of randomized trials for hepatocellular carcinoma treated with percutaneous ablation therapies. Hepatology 2009:49:453-9.

113 Germani G, Pleguezuelo M, Gurusamy K, et al. Clinical outcomes of radiofrequency ablation, percutaneous alcohol and acetic acid injection for hepatocelullar carcinoma: a meta-analysis. J Hepatol 2010;52:380-8.

114 Peng ZW, Zhang YJ, Chen MS, et al. Radiofrequency ablation with of without transcatheter arterial chemoembolization in the treatment of hepatocellular carcinoma: a prospective randomized trial. J Clin Oncol 2013;31:426-32.

115 Burrel M, Reig M, Forner A, et al. Survival of patients with hepatocellular carcinoma treated by transarterial chemoembolisation (TACE) using Drug Eluting Beads. Implications for clinical practice and trial design. J Hepatol 2012:56:1330-5.

116 Malagari K, Pomoni M, Moschouris $\mathrm{H}$, et al. Chemoembolization with doxorubicin-eluting beads for unresectable hepatocellular carcinoma: five-year survival analysis. Cardiovasc Intervent Radiol 2012:35:1119-28.

117 Varela M, Real MI, Burrel M, et al. Chemoembolization of hepatocellular carcinoma with drug eluting beads: efficacy and doxorubicin pharmacokinetics. J Hepatol 2007;46:474-81.

118 Lencioni, Llovet JM, Han G, et al. Sorafenib or placebo in combination with transarterial chemoembolization (TACE) with doxorubicin-eluting beads (DEBDOX) for intermediate-stage hepatocellular carcinoma (HCC): phase II, randomized, double-blind SPACE trial. J Clin Oncol 2012;30:(Suppl 4): abstr LBA154.

119 Kudo M, Imanaka K, Chida N, et al. Phase III study of sorafenib after transarterial chemoembolisation in Japanese and Korean patients with unresectable hepatocellular carcinoma. Eur J Cancer 2011;47:2117-27

120 Salem R, Mazzaferro V, Sangro B. Yttrium 90 radioembolization for the treatment of hepatocellular carcinoma: biological lessons, current challenges, and clinical perspectives. Hepatology 2013;58:2188-97.

121 Salem R, Lewandowski RJ, Mulcahy MF, et al. Radioembolization for hepatocellular carcinoma using Yttrium-90 microspheres: a comprehensive report of long-term outcomes. Gastroenterology 2010;138:52-64.

122 Sangro B, Carpanese L, Cianni R, et al. Survival after yttrium-90 resin microsphere radioembolization of hepatocellular carcinoma across Barcelona clinic liver cancer stages: a European evaluation. Hepatology 2011;54:868-78.

123 Llovet JM, Ricci S, Mazzaferro V, et al. Sorafenib in advanced hepatocellular carcinoma. N Engl J Med 2008;359:378-90.

124 Cheng AL, Kang YK, Chen Z, et al. Efficacy and safety of sorafenib in patients in the Asia-Pacific region with advanced hepatocellular carcinoma: a phase III randomised, double-blind, placebo-controlled trial. Lancet Oncol 2009;10: 25-34.

125 Llovet JM, Decaens T, Raoul JL, et al. Brivanib in patients with advanced hepatocellular carcinoma who were intolerant to sorafenib or for whom sorafenib failed: results from the randomized phase III BRISK-PS study. J Clin Oncol 2013:31:3509-16.

126 Cheng AL, Kang YK, Lin DY, et al. Sunitinib versus sorafenib in advanced hepatocellular cancer: results of a randomized phase III trial. J Clin Oncol 2013;31:4067-75

127 Poon RT, Fan ST, Lo CM, et al. Long-term survival and pattern of recurrence after resection of small hepatocellular carcinoma in patients with preserved liver function: implications for a strategy of salvage transplantation. Ann Surg 2002;235:373-82

128 Johnson PJ, Qin S, Park JW, et al. Brivanib versus sorafenib as first-line therapy in patients with unresectable, advanced hepatocellular carcinoma: results from the randomized phase III BRISK-FL study. J Clin Oncol 2013;31:3517-24.

129 Zhu A, Rosmorduc 0, Evans J, et al. SEARCH: a phase III, randomized, double-blind, placebo-controlled trial of sorafenib plus erlotinib in patients with hepatocellular carcinoma (HCC). Ann Oncol 2012;23(Suppl 9):abstract LBA2.

130 Calin C, Shukui Q, Wen-Tsung H, et al. Phase III trial of linifanib versus sorafenib in patients with advanced hepatocellular carcinoma (HCC). J Clin Oncol 2013;30 (Suppl 34): abstr 249 
131 Zhu A. EVOLVE-1: phase 3 study of everolimus for advanced HCC that progressed during or after sorafenib. J Clin Oncol 2014;32:(Suppl 3):abstract 172.

132 Santoro A, Rimassa L, Borbath I, et al. Tivantinib for second-line treatment of advanced hepatocellular carcinoma: a randomised, placebo-controlled phase 2 study. Lancet Oncol 2012;14:55-63.
133 Boozari B, Mundt B, Woller N, et al. Antitumoural immunity by virus-mediated immunogenic apoptosis inhibits metastatic growth of hepatocellular carcinoma. Gut 2010;59:1416-26.

134 Heo J, Reid T, Ruo L, et al. Randomized dose-finding clinical trial of oncolytic immunotherapeutic vaccinia JX-594 in liver cancer. Nat Med 2013;19:329-36. 